\title{
Nutritional status evaluation in patients affected by Bethlem myopathy and Ullrich congenital muscular dystrophy
}

\author{
Silvia Toni ${ }^{1}$, Riccardo Morandi ${ }^{1}$, Marcello Busacchi ${ }^{1}$, Lucia Tardini ${ }^{1}$, Luciano Merlini ${ }^{2}$, Nino Carlo Battistini ${ }^{1}$ \\ and Massimo Pellegrini ${ }^{1}$ *
}

1 Laboratory of Nutrition and Lifestyle, Department of Diagnostic, Clinical and Public Health Medicine, Modena, Italy

${ }^{2}$ Laboratory of Musculoskeletal Cell Biology, Istituto Ortopedico Rizzoli, Bologna, Italy

Edited by:

Emanuele Marzetti, Catholic

University of the Sacred Heart, Italy

Reviewed by:

Anna Maria Colangelo, University of

Milano-Bicocca, Italy

Mariangela Rondanelli, University of

Pavia, Italy

*Correspondence:

Massimo Pellegrini, University of

Modena and Reggio Emilia, Italy

e-mail: massimo.pellegrini@

unimore.it
Collagen VI mutations lead to disabling myopathies like Bethlem myopathy (BM) and Ullrich congenital muscular dystrophy (UCMD). We have investigated the nutritional and metabolic status of one UCMD and seven BM patients (five female, three male, mean age $31 \pm 9$ years) in order to find a potential metabolic target for nutritional intervention. For this study, we used standard anthropometric tools, such as BMI evaluation and body circumference measurements. All results were compared to dual-energy X-ray absorptiometry (DXA), considered the "gold standard" method. Energy intake of each patient was evaluated through longitudinal methods (7-day food diary) while resting energy expenditure (REE) was predicted using specific equations and measured by indirect calorimetry. Clinical evaluation included general and nutritional blood and urine laboratory analyses and quantitative muscle strength measurement by hand-held dynamometry. BM and UCMD patients showed an altered body composition, characterized by low free fat mass (FFM) and high fat mass (FM), allowing us to classify them as sarcopenic, and all but one as sarcopenic-obese. Another main result was the negative correlation between REE/FFM ratio (basal energy expenditure per kilograms of fat-free mass) and the severity of the disease, as defined by the muscle megascore (correlation coefficient $-0.955, P$-value $<0.001$ ). We postulate that the increase of the REE/FFM ratio in relation to the severity of the disease may be due to an altered and pathophysiological loss of energetic efficiency at the expense of skeletal muscle. We show that a specific metabolic disequilibrium is related to the severity of the disease, which may represent a target for a nutritional intervention in these patients.

Keywords: collagen VI, muscular dystrophies, nutritional assessment, body composition, basal energy expenditure

\section{INTRODUCTION}

Mutations in the genes COL6A1, COL6A2, and COL6A3, coding for three $\alpha$ chains of collagen type VI, cause COL6-related myopathies (COL6-RM), including the severe Ullrich congenital muscular dystrophy (UCMD), the milder Bethlem myopathy (BM) (Bertini and Pepe, 2002; Allamand et al., 2010), and the Myosclerosis Myopathy in a single family (Merlini et al., 2008a,b).

The prevalence of UCMD and BM has been calculated as 0.13 per 100,000 and 0.77 per 100,000, respectively (Norwood et al., 2009). BM (MIM \#158810) (Merlini et al., 1994) is characterized by axial and proximal muscle wasting and weakness with finger flexion contractures. BM is usually mild, sometimes slowly progressive (Pepe et al., 2002). BM has both dominant and recessive inheritance (Gualandi et al., 2009). Immunohistochemistry shows normal or mildly reduced levels of ColVI in the endomysium of most BM patients (Allamand et al., 2010). UCMD (MIM \#254090) (Mercuri et al., 2005) is a severe congenital muscular dystrophy, characterized by early onset, generalized and rapidly progressive muscle wasting and weakness, proximal joint contractures, and distal joint hypermobility. Walking ability is rarely achieved or preserved during adolescence, and the rapid progression of the clinical symptoms usually leads to early death, due to respiratory failure (Mercuri et al., 2005). UCMD is caused both by recessive and de novo dominant mutations (Mercuri et al., 2005). ColVI appears to be strongly reduced or absent in muscle biopsies from UCMD patients.

A dystrophic mouse model, where collagen VI synthesis was prevented by targeted inactivation of the Col6al gene, allowed the investigation of the pathogenesis, revealing the existence of a $\mathrm{Ca}(2+)$-mediated dysfunction of the mitochondria and sarcoplasmic reticulum and defective autophagy (Bernardi and Bonaldo, 2013). Similar defects contribute to the disease pathogenesis in patients, irrespective of the genetic lesion causing the collagen VI defect (Irwin et al., 2003; Grumati et al., 2010). These studies indicate that permeability transition pore opening and defective autophagy represent key elements of skeletal muscle fiber death, and provide a rationale for the use of cyclosporin A (Merlini et al., 2008a,b) and of nutritional interventions to correct defective autophagy (Merlini et al., 2014) in patients affected by COL6-RM, a strategy that holds great promise for treatment.

In the last decade, several studies have demonstrated that nutritional status and body composition are strictly related to clinical 
outcomes and that nutritional intervention can be effective in the prevention and treatment of many diseases related to metabolism, bioenergetics, and even cancer.

According to a three-compartment model of body composition (Moon et al., 2008), total body weight is the sum of lean mass (LM), fat mass (FM), and bone mineral content (BMC). The LM, which includes the mass of the internal organs and that of the muscles, together with the BMC, form the fat-free mass (FFM), which represents the more metabolically active component of the human body. A "pathological" ratio between FFM and FM and/or an abnormal distribution of these components in the body, mainly trunk versus appendages, is found in many pathological conditions and correlates with the severity of the metabolic or energy status alteration; moreover, modifications of body composition per se may represent an independent health risk factor (Wohlfahrt et al., 2014). Augmented FM leads to a higher cardiometabolic risk and to a higher incidence of hypertension, diabetes (Rohan et al., 2013), and cardiovascular diseases.

Muscular dystrophies (MD) are characterized by progressive deterioration of muscle mass, muscle strength, and function. Resting energy expenditure (REE), which comprises $70 \%$ of daily energy needs, is determined by the amount and composition of the metabolically active fat-free mass (FFM). The reduced muscle mass and muscular activity, characteristic of MDs, could result in a significant parallel decrease in REE. Surprisingly, it was found that that patients with Emery-Dreifuss MD (Vaisman et al., 2004) and Duchenne and Becker MD (Zanardi et al., 2003a; GonzalezBermejo et al., 2005; Hogan, 2008; Elliott et al., 2012) may have increased energy expenditure. If not met with increased caloric intake, this greater energy expenditure may partially contribute to further deterioration in their muscle mass and function.

It has already been shown that patients with COL6-RM have reduced muscle mass, muscle strength, and muscle function (Miscione et al., 2013). To date, no data are available on the energy expenditure in COL6-RM. The aim of this study is to investigate the relationship between REE, body composition, and muscle strength in COL6-RM.

\section{MATERIALS AND METHODS PATIENTS}

We analyzed eight adult patients (five women, three men, mean age $31 \pm 9$ years) with COL6-RM: seven had BM and one UCMD. The UCMD patient was never able to walk and was on nocturnal noninvasive mechanical ventilation. This study was approved by the institutional ethical committee of the Istituto Ortopedico Rizzoli (ClinicalTrials.gov identifier: NCT01438788). All subjects were fully informed about the study and gave their written informed consent.

\section{BODY COMPOSITION}

Nutritional status was evaluated throughout the study by both non-invasive and invasive techniques (El Ghoch et al., 2014). Body composition was obtained by DXA (Hologic $4500 \mathrm{~W}$; software version 11.2; Hologic, Inc., Waltham, MA, USA) software, which provides regional and whole-body estimation of LM, FM, and $\mathrm{BMC}$, according to the three-compartment model of body composition. FFM was calculated as the sum of LM and BMC, and has been provided for each body part (i.e., trunk and limbs) (Scaglioni et al., 2013). From these whole-body measures, the following derivative values were calculated: FMI (FM/height2), LM/height2, appendicular lean mass/height2 (ALMI). Appendicular lean mass (ALM) was the sum of bone-free and fat-free tissue masses in the arms and legs. Sarcopenic obesity was defined, according to Baumgartner et al. (2004), as ALM divided by stature squared (ALMI) less than $7.26 \mathrm{~kg} / \mathrm{m}^{2}$ in men and $5.45 \mathrm{~kg} / \mathrm{m}^{2}$ in women and percentage body fat, derived by DXA, greater than $28 \%$ in men and $40 \%$ in women (Baumgartner et al., 2004).

Anthropometric measurements included: body weight (Wt), height (Ht), and circumferences [waist, hip, waist-hip ratio (WHR)].All measurements were determined by the same operator following the Anthropometric Standardization Reference Manual recommendations (Lohman et al., 1988). Body mass index (BMI) was calculated as Wt $\left[\mathrm{Kg} / \mathrm{Ht}\left(\mathrm{m}^{2}\right)\right]$. We used BMI to categorized participants as obese $(\mathrm{BMI} \geq 30)$, overweight $(25 \leq \mathrm{BMI}<30)$, normal weight $(18.5<\mathrm{BMI}<25)$, or underweight $\leq 18.5$.

\section{ENERGY AND NITROGEN BALANCE}

Resting energy expenditure was estimated by indirect calorimetry using a metabolic measurement cart with a canopy hood (CareFusion Vmax Encore, San Diego, CA, USA). Subjects were instructed to fast for $12 \mathrm{~h}$ and abstain from exercise for $24 \mathrm{~h}$ before the test (Mifflin et al., 1990). Before measuring REE, all subjects were asked to rest quietly in the supine position for approximately 30-40 min in an isolated room, with a temperature between $21^{\circ}$ and $24^{\circ} \mathrm{C}$. The criterion for a valid REE was 15 min of steady state, determined as $<5 \%$ variation in respiratory quotient (RQ)/minute and oxygen consumption/minute. Oxygen consumption and carbon dioxide production were used to calculate REE, in accordance with the Weir equation (Turell and Alexander, 1964). REE were also calculated with the equations based on weight, height, age, and sex [Harris-Benedict and Schofield (Energy and protein requirements. Report of a joint FAO/WHO/UNU expert consultation, 1985; Roza and Shizgal, 1984)] using the free fat mass (FFM)-based predictive equations of Mifflin and Katch and McArdle (McArdle et al., 1986; Mifflin et al., 1990).

Food intake was evaluated by a 7-day food diary and a dietitian interview (O'Connor et al., 2014). Nitrogen balance, an important tool for estimating adequate protein intake (Tarnopolsky et al., 1988), was calculated as the difference between nitrogen input ( $24 \mathrm{~h}$ dietary protein intake) and nitrogen output ( $24 \mathrm{~h}$ urinary urea nitrogen).

General and nutritional blood and urine laboratory analyses (albumin: transferrin; creatinine; uric acid; glucose; triglycerides: total, HDL, and LDL cholesterol; urinary creatinine; and nitrogen) were taken to assess the metabolic status of the patients. The 24-h urinary creatinine excretion value was used as an index of protein nutrition; the creatinine height index $(\mathrm{CHI})$ and lean body mass was estimated from this value.

\section{MUSCLE STRENGTH}

A composite score (megascore) was calculated by summing the maximal force of eight physical tests (Bryan et al., 2003; Merlini et al., 2003) using a hand-held dynamometer (Type CT 3001, Citec, C.I.T. Technics BV, Groningen, The Netherlands) (Van der Ploeg 
et al., 1991; Beenakker et al., 2001). Four muscle groups were examined bilaterally: hand grip, elbow flexors, knee extensors, and knee flexors (Merlini et al., 2002, 2003, 2004). Each individual muscle group was tested for at least $3 \mathrm{~s}$ using a "make" test (Merlini et al., 2004). The maximum force from three attempts was used in the analysis.

\section{STATISTIC ANALYSIS}

Pearson correlation coefficients were calculated to study the association between different parameters. Statistical significance was set at 0.05. All analyses were conducted using the STATA software package for Windows 13.1 (Stata Corp, College Station, TX, USA). Measurable variables are presented as mean \pm SD and categorical data as number and percentage.

\section{RESULTS}

\section{ANTHROPOMETRIC EVALUATION}

Anthropometric analysis showed that UCMD and BM patients have average BMI values in the range of normality, comparable with a healthy population (Janssen et al., 2002). Body circumference measurements do not show any significant variations from normality (Janssen et al., 2002) (Table 1).

\section{BODY COMPOSITION ANALYSIS}

Body composition analysis showed quantitative changes in all the partitions of the body. All the patients had a loss of muscle mass, as shown by a marked reduction of FFM, FFMI, and ALMI, and augmented FM, as indicated by \% FM and FMI.

In particular, all patients were sarcopenic, based on ALMI, and seven were sarcopenic-obese, based on ALMI and \% FM (Tables 2 and 3).

Table 1 | Anthropometric analysis.

\begin{tabular}{lll}
\hline & $\mathbf{M}(\boldsymbol{n}=\mathbf{3})$ & $\mathbf{W}(\boldsymbol{n}=\mathbf{5})$ \\
\hline Body weight $(\mathrm{Kg})$ & 67.40 & 61.24 \\
& $( \pm 11.39)$ & $( \pm 12.34)$ \\
Body height $(\mathrm{m})$ & 1.72 & 1.63 \\
& $( \pm 0.01)$ & $( \pm 0.05)$ \\
BMI $\left(\mathrm{Kg} / \mathrm{m}^{2}\right)$ & 22.73 & 23.05 \\
& $( \pm 3.72)$ & $( \pm 4.25)$ \\
Waist circumference $(\mathrm{cm})$ & $(\mathrm{N} . \mathrm{V} .18 .5-24.9)$ & $(\mathrm{N} . \mathrm{V} .18 .5-24.9)$ \\
& 83.83 & 74.85 \\
& $( \pm 8.78)$ & $( \pm 7.19)$ \\
Hip circumference $(\mathrm{cm})$ & $(\mathrm{N} . \mathrm{V} .<94)$ & $(\mathrm{N} . \mathrm{V} .<80)$ \\
& 96.83 & 103.13 \\
waist-hip ratio $(\mathrm{WHR})$ & $( \pm 6.25)$ & $( \pm 13.24)$ \\
& 0.86 & 0.72 \\
& $( \pm 0.05)$ & $( \pm 0.05)$ \\
& $(\mathrm{N} . \mathrm{V} .<1)$ & $(\mathrm{N} . \mathrm{V} .<0.85)$ \\
& &
\end{tabular}

The table shows the values obtained from the standard anthropometric analysis. For each parameter, the mean values $\pm S D$ are presented. When possible, normal values (N.V.) were reported ( $M$, men and $W$, women).
Moreover, from the DXA data (trunk-to-limb FM ratio) and anthropometric parameters (waist circumference and waist/hip ratio index), we can deduce that, in the two compartments, the increased fat tissue was equally distributed (DXA) compensating for the loss of muscle mass (circumferences).

Bone mineral content, the other component of the FFM, is also strongly reduced in these patients, especially in men. The data are confirmed by $T$-score calculations in our male patients (Male $T$ score -1.87 ). $T$-score is a diagnostic for osteopenia (Kanis et al., 2013) (Tables 2 and 3 ).

\section{BLOOD, URINE BIOCHEMICAL ANALYSIS, AND NITROGEN BALANCE}

Blood and urine analysis do not show any specific pathological modification. In particular, although seven out of eight patients were obese, according to \% fat determined by DXA, none had high levels of blood triglycerides, total cholesterol, HDL, or LDL (Jukema and Simoons, 1999). Blood creatinine levels were

Table 2 | Dual-energy X-ray absorptiometry.

\begin{tabular}{|c|c|c|}
\hline & $\mathrm{M}(n=3)$ & $\mathrm{W}(n=5)$ \\
\hline Fat-free mass (FFM) (\%) & $\begin{array}{l}62.03 \\
( \pm 18.19)\end{array}$ & $\begin{array}{l}48.36 \\
( \pm 6.55)\end{array}$ \\
\hline Fat-free mass (FFM) (Kg) & $\begin{array}{l}42.39 \\
( \pm 4.08)\end{array}$ & $\begin{array}{l}29.22 \\
( \pm 3.53)\end{array}$ \\
\hline FFMI (FFM/height $\left.{ }^{2}\right)\left(\mathrm{Kg} / \mathrm{m}^{2}\right)$ & $\begin{array}{l}14.43 \\
( \pm 1.27)\end{array}$ & $\begin{array}{l}10.90 \\
( \pm 0.85)\end{array}$ \\
\hline Fat mass (FM) (\%) & $\begin{array}{l}34.63 \\
( \pm 14.21)\end{array}$ & $\begin{array}{l}51.64 \\
( \pm 6.55)\end{array}$ \\
\hline Fat mass (FM) (Kg) & $\begin{array}{l}23.86 \\
( \pm 12.05)\end{array}$ & $\begin{array}{l}31.93 \\
( \pm 9.76)\end{array}$ \\
\hline FMI (FM/height $\left.{ }^{2}\right)\left(\mathrm{Kg} / \mathrm{m}^{2}\right)$ & $\begin{array}{l}8.18 \\
( \pm 4.20)\end{array}$ & $\begin{array}{l}12.07 \\
( \pm 3.71)\end{array}$ \\
\hline Bone mineral content (BMC) (\%) & $\begin{array}{l}3.16 \\
( \pm 0.61)\end{array}$ & $\begin{array}{l}3.06 \\
( \pm 0.84)\end{array}$ \\
\hline Bone mineral content (BMC) $(\mathrm{Kg})$ & $\begin{array}{l}2.08 \\
( \pm 0.04)\end{array}$ & $\begin{array}{l}1.82 \\
( \pm 0.36)\end{array}$ \\
\hline$T$-score & $\begin{array}{l}-1.87 \\
( \pm 0.49)\end{array}$ & $\begin{array}{l}-0.23 \\
( \pm 0.86)\end{array}$ \\
\hline Trunk-to-limb fat mass ratio & $\begin{array}{l}1.10 \\
( \pm 0.03)\end{array}$ & $\begin{array}{l}0.82 \\
( \pm 0.06)\end{array}$ \\
\hline ALMI $\left(\mathrm{Kg} / \mathrm{m}^{2}\right)$ & $\begin{array}{l}5.68 \\
( \pm 0.57)\end{array}$ & $\begin{array}{l}4.25 \\
( \pm 1.43)\end{array}$ \\
\hline ALM $(\mathrm{Kg})$ & $\begin{array}{l}9.79 \\
( \pm 1.01)\end{array}$ & $\begin{array}{l}6.92 \\
( \pm 2.35)\end{array}$ \\
\hline Trunk lean mass (Kg) & $\begin{array}{l}21.35 \\
( \pm 2.24)\end{array}$ & $\begin{array}{l}14.66 \\
( \pm 1.12)\end{array}$ \\
\hline Trunk fat mass (Kg) & $\begin{array}{l}11.85 \\
( \pm 6.13)\end{array}$ & $\begin{array}{l}13.70 \\
( \pm 5.11)\end{array}$ \\
\hline
\end{tabular}

The table shows DXA body composition values. Mean values $\pm S D$ are presented $(M$, men and $W$, Women). 
Table 3 | Body composition values obtained by anthropometric and DXA analyses, in BM and UCMD patients, compared to a healthy population

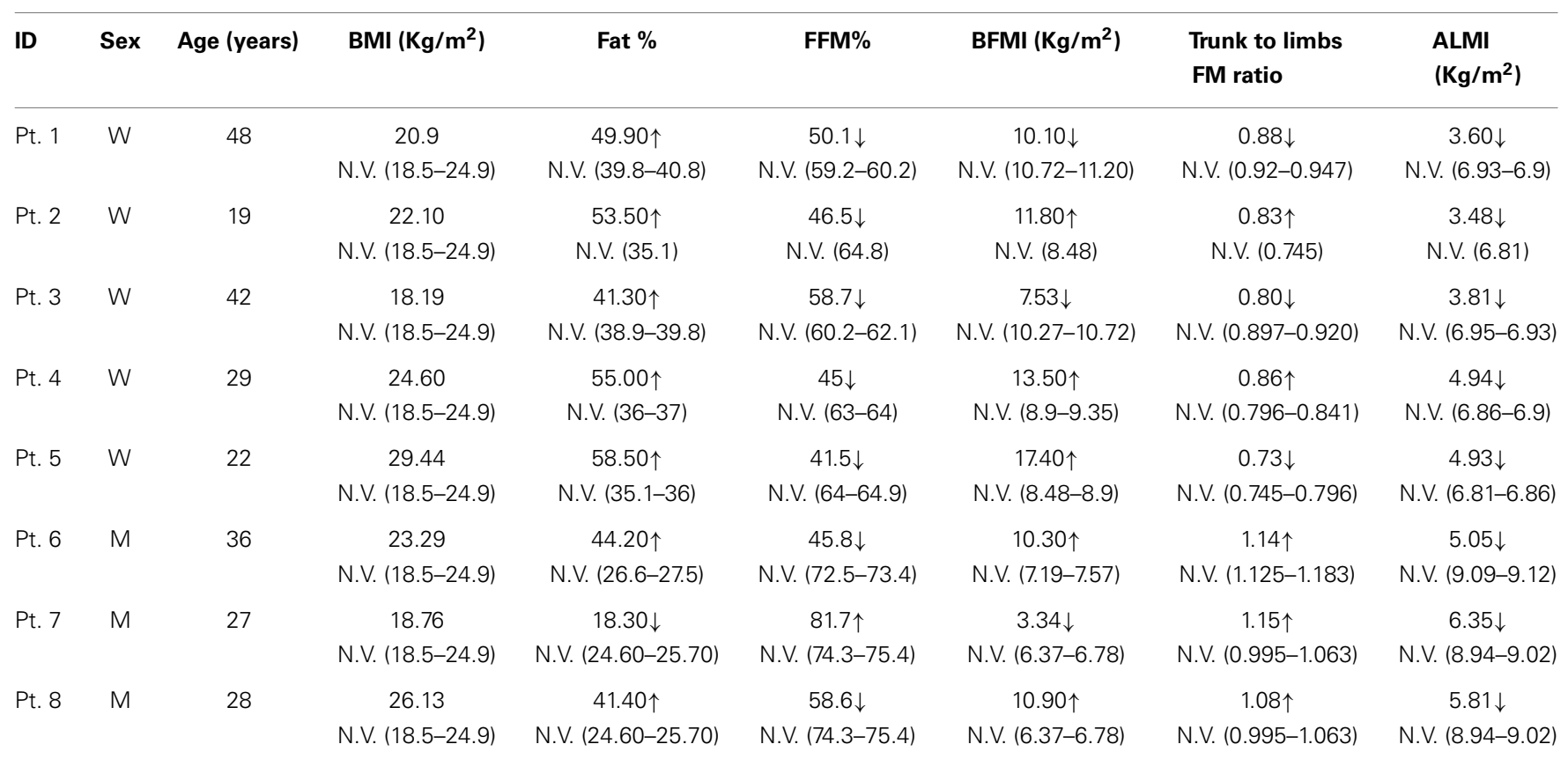

The table shows the body composition values of our subjects ( $M$, men and F, women) compared to healthy values reported in the literature (Kelly et al., 2009; Wang et al., 2010). We used: "个" when the values were increased; " $\downarrow$ " when the values were low.

moderately decreased (Ballesteros et al., 1994), particularly in women. Urinary creatine levels were generally low, particularly in men. Consequently, calculated $\mathrm{CHI}$, an index of muscle mass (Rosenfalck et al., 1994), was greatly reduced in UCMD and BM patients.

Nitrogen balance was in the normal range.

Moreover, megascore values in our patients reflect the low strength condition typical of MDs (Table 4).

\section{RESTING ENERGY EXPENDITURE AND RESPIRATORY OUOTIENT}

Resting energy expenditure was measured by indirect calorimetry and estimated by specific predictive equations. The REEs estimated by the equations based on weight, height, age, and sex accurately predicted the same values measured with indirect calorimetry [Harris-Benedict and Schofield ("Energy and protein requirements. Report of a joint $\mathrm{FAO} / \mathrm{WHO} / \mathrm{UNU}$ Expert Consultation," 1985; Roza and Shizgal, 1984)]. REE was instead severely underestimated using the FFM-based predictive equations of Mifflin and Katch and McArdle (McArdle et al., 1986; Mifflin et al., 1990). Hence, considering that these patients are characterized by a reduced FFM in kilograms, we can deduce that there is a relative hypermetabolic state (Müller, 2007) with a higher ratio of REE (kcal)/FFM (kg) (Figure 1).

Measured RQs values are indicative of a mixed nutrient-based metabolism. However, there was a sex difference concerning the type of substrates utilized. While male patients had a higher carbohydrate-based metabolism ( $57.67 \pm 14.57 \%$ carbohydrates), women showed a higher lipid-based metabolism $(56.00 \pm 16.39 \%$ lipids) (Table 5) (Figure 2). There was a strong positive correlation between the quantity of FFM in $\mathrm{kg}$ and the percentage of carbohydrates metabolized during REE. This correlation, however, was negative for the percentage of lipids metabolized. No correlation was found between the percentage of proteins used as a metabolic substrate and FFM.

All in all, patients are characterized by an augmented REE per kilogram of FFM; additionally, subjects with higher FFM values metabolize more carbohydrates and less lipids then the ones with minor FFM levels (Figure 3).

\section{MUSCLE STRENGTH}

Megascores expressed as the sum of the muscle strength of eight different tests, were 1093.33 ( \pm 306.37$)$ Newton in men and 572.60 $( \pm 233.11)$ in women. These values were markedly reduced, as muscle strength was low in all muscle groups, compared with the normative values (Van der Ploeg et al., 1991; Beenakker et al., 2001).

There was a strong correlation between muscle strength, expressed as Megascore, and the various indices of muscle mass, but no correlation with the indices of body fat. A strong correlation was found between Megascore and blood creatinine. This correlation was even stronger with urinary creatinine and the derived index "CHI" (Figure 6). UCMD and BM patients who had a higher FFM showed a better performance in the muscle strength tests. The Megascore was directly proportional to FFM in kilograms and inversely proportional to the REE/FFM ratio (Figure 4).

This trend is maintained in the correlation between the Megascore and both trunk and limbs FFM. However, the linear correlation coefficient was higher between Megascore and appendicular FFM than Megascore and Trunk FFM (Figure 5). FFM\% also correlated with Megascore, but the correlation was weaker. 
Table 4 | Clinical and laboratory data.

\begin{tabular}{|c|c|c|}
\hline & $\operatorname{Men}(n=3)$ & Women $(n=5)$ \\
\hline Creatinine $(\mathrm{mg} / \mathrm{dL})$ & $\begin{array}{l}0.64 \\
( \pm 0.30) \\
\text { N.V. (0.8-1.3) }\end{array}$ & $\begin{array}{l}0.26 \\
( \pm 0.07) \\
\text { N.V. (0.6-1.1) }\end{array}$ \\
\hline Urinary creatinine (mg/24 h) & $\begin{array}{l}893.33 \\
( \pm 347.04) \\
\text { N.V. }(500-2000)\end{array}$ & $\begin{array}{l}394.00 \\
( \pm 107.84) \\
\text { N.V. }(500-2000)\end{array}$ \\
\hline Creatinine height index (CHI) (\%) & $\begin{array}{l}57.63 \\
( \pm 22.45) \\
\text { N.V. (109) }\end{array}$ & $\begin{array}{l}39.19 \\
( \pm 10.83) \\
\text { N.V. (110) }\end{array}$ \\
\hline Dietary $\mathrm{CHO}$ intake (g) & $\begin{array}{l}342.56 \\
( \pm 48.17)\end{array}$ & $\begin{array}{l}197.62 \\
( \pm 62.38)\end{array}$ \\
\hline Dietary lipid intake (g) & $\begin{array}{l}89.05 \\
( \pm 27.47) 0\end{array}$ & $\begin{array}{l}63.62 \\
( \pm 27.55)\end{array}$ \\
\hline Dietary protein intake $(\mathrm{g})$ & $\begin{array}{l}83.58 \\
( \pm 8.90)\end{array}$ & $\begin{array}{l}68.12 \\
( \pm 26.02)\end{array}$ \\
\hline Nitrogen intake (g) & $\begin{array}{l}13.37 \\
( \pm 1.42)\end{array}$ & $\begin{array}{l}10.90 \\
( \pm 4.16)\end{array}$ \\
\hline Urinary urea nitrogen $(\mathrm{g})$ & $\begin{array}{l}13.04 \\
( \pm 1.08)\end{array}$ & $\begin{array}{l}11.99 \\
( \pm 3.48)\end{array}$ \\
\hline Nitrogen balance & $\begin{array}{l}-0.67 \\
( \pm 1.67) \\
\text { N.V. }(0.00)\end{array}$ & $\begin{array}{l}-1.84 \\
( \pm 1.30 \\
\text { N.V. }(0.00)\end{array}$ \\
\hline Megascore & $\begin{array}{l}1093.33 \\
( \pm 306.37)\end{array}$ & $\begin{array}{l}572.60 \\
( \pm 233.11)\end{array}$ \\
\hline
\end{tabular}

The table shows the biochemical values obtained from blood and urine analysis and Megascore (Merlini et al., 2002, 2004). For each parameter, the mean values $\pm S D$ are presented. When possible, normal values (N.V.) were reported (M, men and $W$, women).

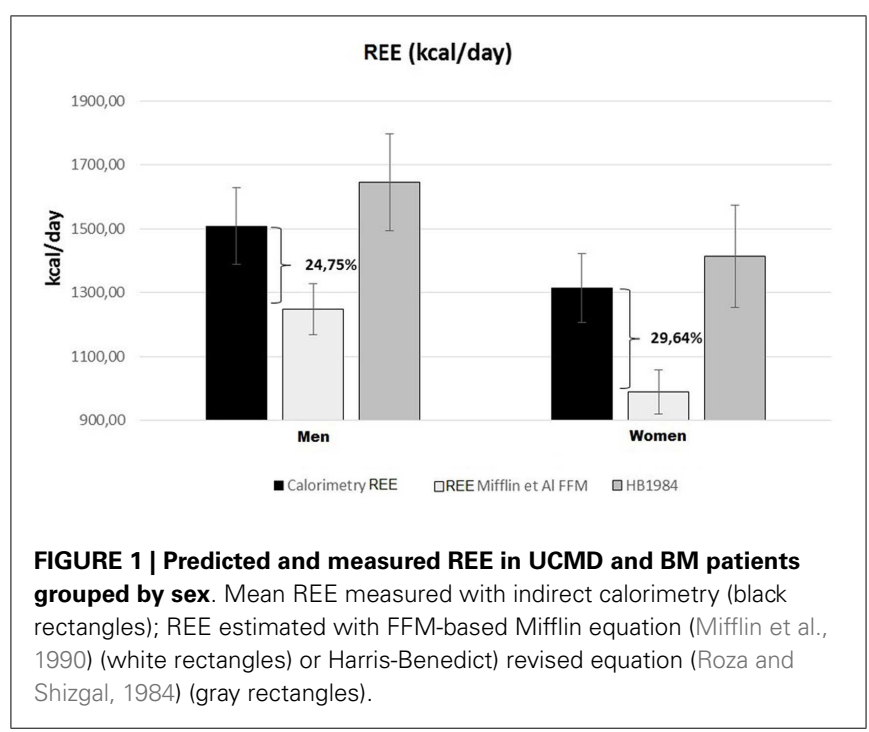

No correlation was found any between the Megascore and the indices of fat mas, FM in kilograms, FM percentage, or REE/FM ratio.
Table 5 | Energy balance.

\begin{tabular}{|c|c|c|}
\hline & $M(n=3)$ & $W(n=5)$ \\
\hline REE indirect calorimetry (Kcal) & $\begin{array}{l}1508.33 \\
( \pm 120.03)\end{array}$ & $\begin{array}{l}1315.02 \\
( \pm 107.55)\end{array}$ \\
\hline REE Mifflin et Al (Kcal) & $\begin{array}{l}1248.09 \\
( \pm 80.28)\end{array}$ & $\begin{array}{l}988.67 \\
( \pm 69.62)\end{array}$ \\
\hline REE Katch and McArdle (Kcal) & $\begin{array}{l}1285.63 \\
( \pm 88.02)\end{array}$ & $\begin{array}{l}1001.19 \\
( \pm 76.34)\end{array}$ \\
\hline REE FAO Schofield et al. (Kcal) & $\begin{array}{l}1708.48 \\
( \pm 175.28)\end{array}$ & $\begin{array}{l}1392.91 \\
( \pm 173.51)\end{array}$ \\
\hline REE Harris-Benedict 1984 (Kcal) & $\begin{array}{l}1645.34 \\
( \pm 152.67)\end{array}$ & $\begin{array}{l}1412.83 \\
( \pm 159.62)\end{array}$ \\
\hline $\begin{array}{l}\text { Mifflin FFM/REE } \\
\text { Indirect calorimetry \% }\end{array}$ & $\begin{array}{l}76.25 \\
( \pm 8.28)\end{array}$ & $\begin{array}{l}70.36 \\
( \pm 5.20)\end{array}$ \\
\hline FAO/REE indirect calorimetry \% & $\begin{array}{l}113.15 \\
( \pm 4.14)\end{array}$ & $\begin{array}{l}106.35 \\
( \pm 15.14)\end{array}$ \\
\hline $\begin{array}{l}\text { Harris-Benedict 1984/REE } \\
\text { Indirect calorimetry \% }\end{array}$ & $\begin{array}{l}109.01 \\
( \pm 1.71)\end{array}$ & $\begin{array}{l}107.88 \\
( \pm 14.32)\end{array}$ \\
\hline Respiratory quotient (RQ) & $\begin{array}{l}0.90 \\
( \pm 0.06)\end{array}$ & $\begin{array}{l}0.80 \\
( \pm 0.03)\end{array}$ \\
\hline $\mathrm{RO}$ proteins (\%) & $\begin{array}{l}19.67 \\
( \pm 2.89)\end{array}$ & $\begin{array}{l}20.00 \\
( \pm 9.89)\end{array}$ \\
\hline RQ lipids (\%) & $\begin{array}{l}22.33 \\
( \pm 17.95)\end{array}$ & $\begin{array}{l}56.00 \\
( \pm 16.39)\end{array}$ \\
\hline RO carbohydrates (\%) & $\begin{array}{l}57.67 \\
( \pm 14.57)\end{array}$ & $\begin{array}{l}23.75 \\
( \pm 7.45)\end{array}$ \\
\hline $\mathrm{REE} / \mathrm{FFM}(\mathrm{Kcal} / \mathrm{Kg})$ & $\begin{array}{l}35.77 \\
( \pm 3.92)\end{array}$ & $\begin{array}{l}45.46 \\
( \pm 6.13)\end{array}$ \\
\hline REE/FM (Kcal/Kg) & $\begin{array}{l}80.61 \\
( \pm 51.94)\end{array}$ & $\begin{array}{l}44.54 \\
( \pm 13.75)\end{array}$ \\
\hline
\end{tabular}

In this table, values of indirect calorimetry and predictive equations analysis are presented. For each parameter, the mean values $\pm S D$ are presented $M$, men and $W$, women).

\section{DISCUSSION}

In this study, we have investigated the relationship between body composition, energetic metabolism, and muscle strength in a cohort of patients with COL6-RM.

According to body composition, evaluated by DXA, all patients could be defined as sarcopenic and all but one as sarcopenicobese. The patients showed a marked increment of the amount of FM and a severe loss of FFM without important modifications in the BMI, which ranged from underweight to overweight, or in waist circumferences measures, which were within a normal range. This peculiar modification in body composition can be explained by the process of fatty infiltration of the muscle in MD (Tuffery-Giraud et al., 2004; Jarraya et al., 2012; Willis et al., 2014).

Since FFM is the major determinant of energy expenditure in normal subjects, we integrated body composition analysis with the analysis of energy status and of muscle strength in accordance 


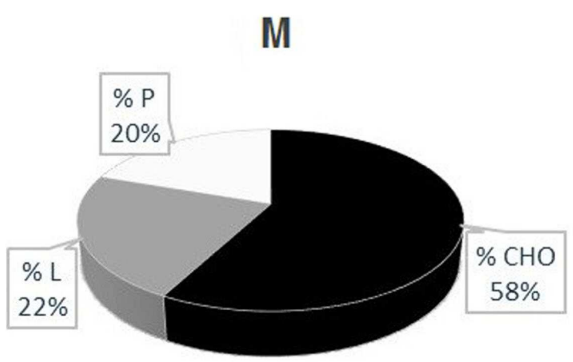

a $\% \mathrm{CHO} \quad$ 国 $\% \mathrm{~L} \quad \square \mathrm{P}$

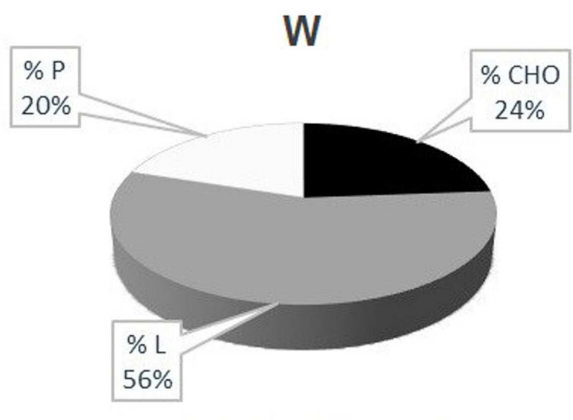

$\% \mathrm{CHO}=\% \mathrm{~L} \quad \square \% \mathrm{P}$
FIGURE 2 | UCMD and BM patients' metabolism. Percentage of Carbohydrates $(\mathrm{CHO})$, Lipids $(\mathrm{L})$ and Proteins $(\mathrm{P})$ utilized during indirect calorimetry examination. These values were calculated from respiratory quotients and urine nitrogen measurement (Livesey and Elia, 1988) Mean values in men (left) and women (right) are reported.

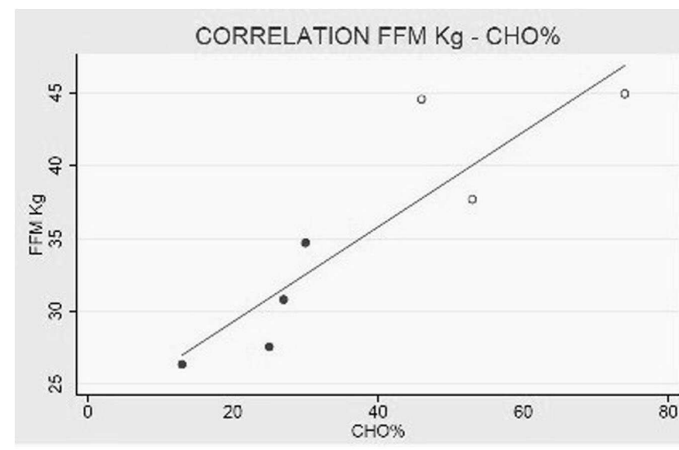

FIGURE 3 | Collagen VI myopathies: FFM metabolism. (Left) Linear correlation between FFM in $\mathrm{kg}$ and percentage of carbohydrates used as metabolic substrate (correlation coefficient $R=0.89$ e $P<0.01$ ), and (right) correlation between FFM and percentage of lipids used as metabolic



substrate (correlation coefficient $R=-0.87$ e $P=0.01$ ). White dots represent men and black dots represent women. The percentage of substrate utilized was calculated using the respiratory quotient and urinary urea nitrogen (Livesey and Elia, 1988). Data from one BM were missing.
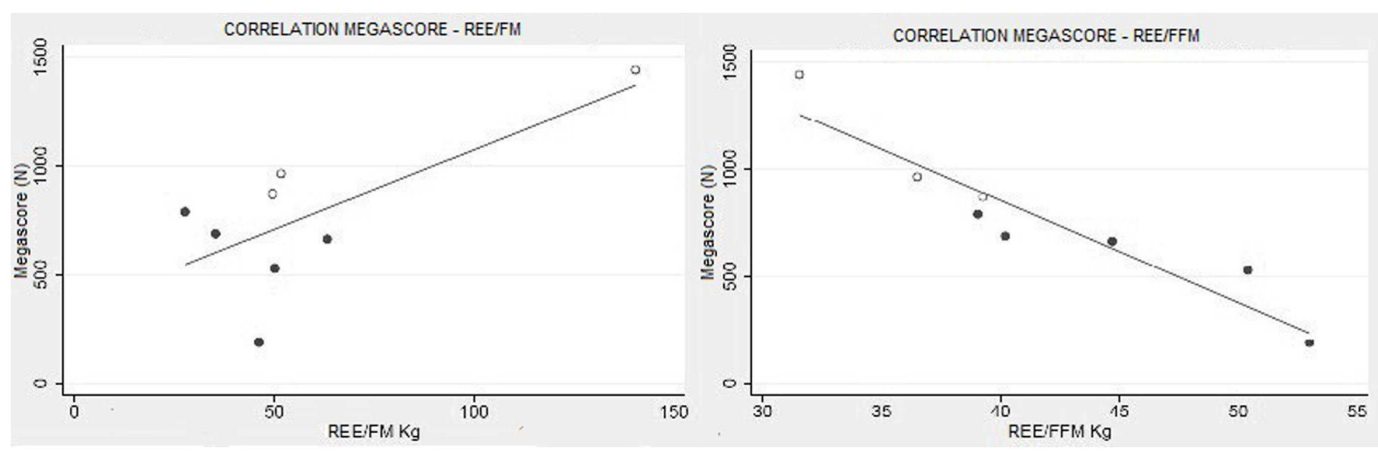

FIGURE 4 | Muscle strength and functional body composition. As expected there was no correlation between Megascore and REE/FM, but instead a strong correlation between Megascore and the REE/FFM ratio $(R=-0.94, P<0.001)$ (right).

with the new concept of functional body composition (Müller et al., 2009).

COL6-RM patients showed a REE, analyzed by indirect calorimetry, in the range of normality, despite the severe reduction of the FFM. Predictive formulas estimate REE values in line with what we actually have found by indirect calorimetry. Applying the concept of functional body composition and relating FFM to energy expenditure, we found a clear deviation from normality 


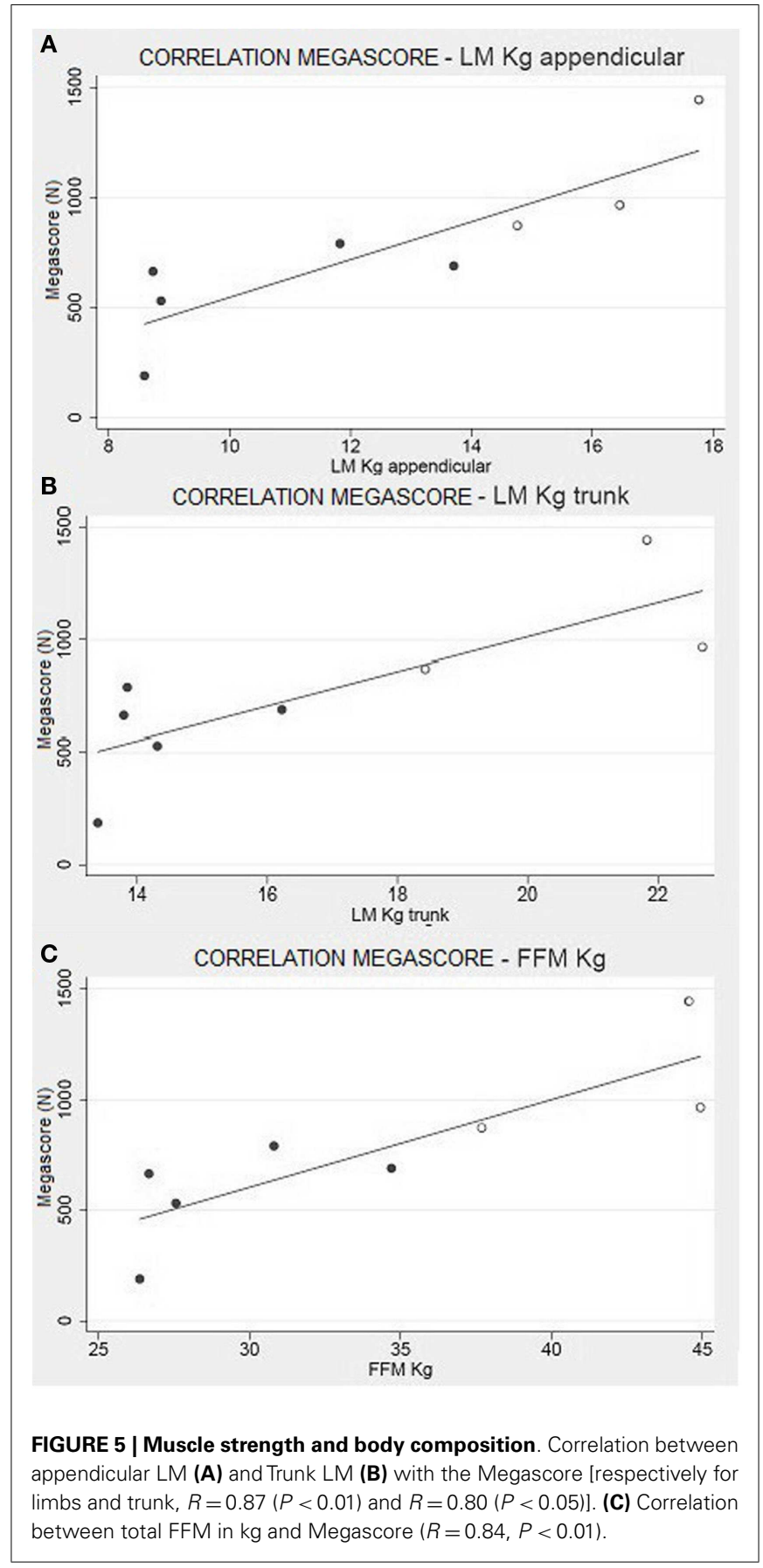

(metabolic disequilibrium) with a considerably augmented REE per kilogram of FFM. Our assumptions are supported by the fact that REE, estimated through FFM-based equations, clearly underestimate the effective metabolism of these patients by $25-30 \%$ (Figure 1).

If we compare the metabolism predicted by FFM-basedformulas with the values of REE, adjusted for body composition, we find that the FFM of these patients is overworking or in a hypermetabolic state (Müller, 2007). A similar metabolic alteration has been reported by Zanardi et al. in Duchenne patients (Zanardi

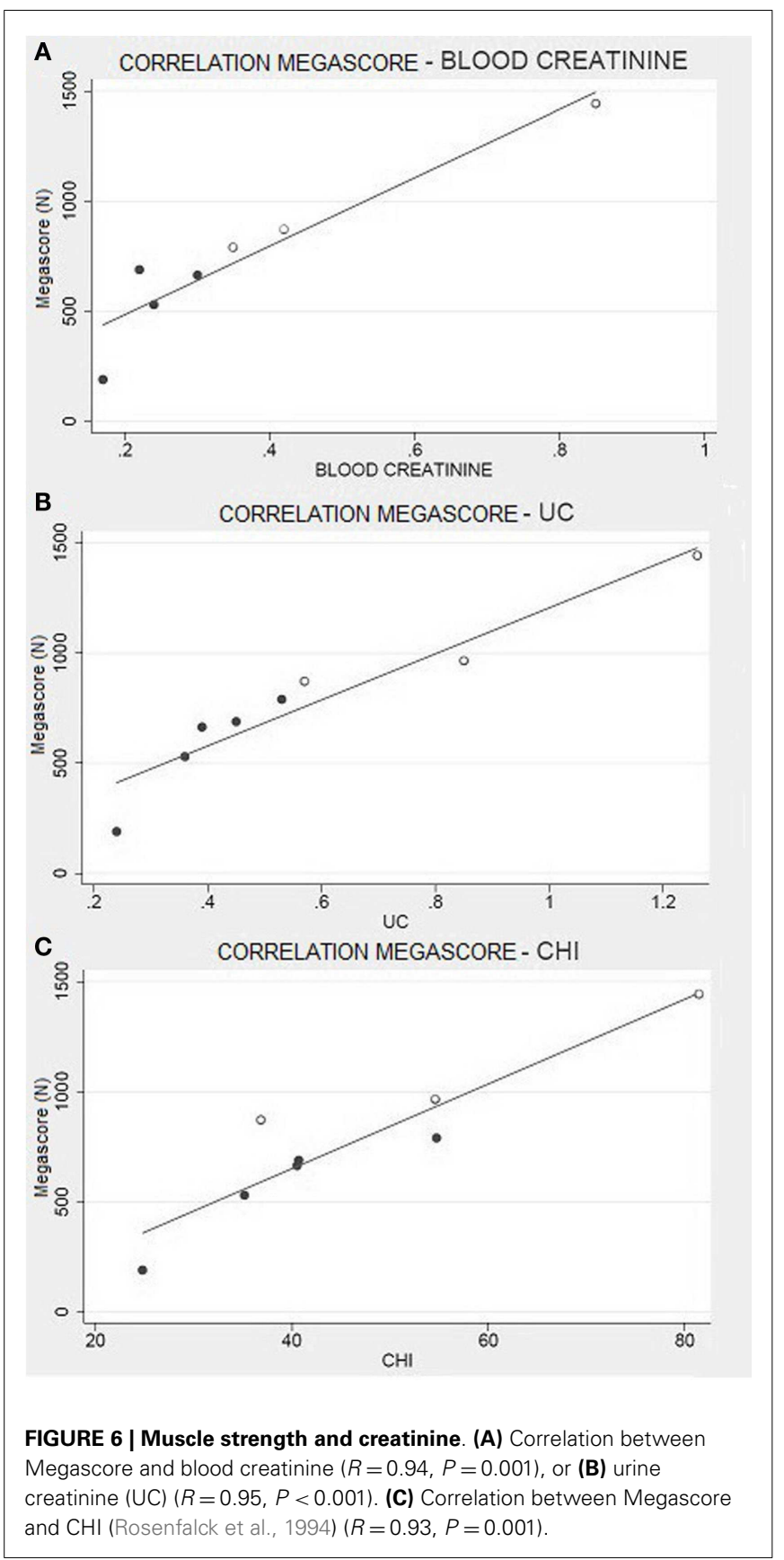

et al., 2003b). It has been considered an enduring enigma: why is the ratio of REE to metabolically active tissue mass, expressed as the REE/FFM ratio, greater in magnitude in subjects with a small FFM than in subjects with a large FFM? (Heymsfield et al., 2002).

In COL6-RM patients, FFM requires more energy than in healthy subjects, and because FFM is made up of muscle and internal organs, we can only speculate as to which of these two components presents a hypermetabolic state. In particular, the augmented REE/FFM ratio could be due to a non-physiological increase in visceral organ metabolism, or to an altered energy expenditure of muscle cells. However, even if our study cannot 
completely answer this question, all evidence suggests that the second hypothesis is the right one.

If we consider the pathological alteration of muscle structures, underlined in mouse model studies (De Palma et al., 2013), with the loss of muscular protein stability leads to a loss of efficiency, and additional energy is necessary to maintain muscle cell homeostasis. Even if this theory has been demonstrated in other studies no one had ever pointed out that this behavior is strictly correlated with the severity of the disease. Our hypothesis is that, in a dystrophic environment, the energy that the muscle has to spend in order to maintain its function is inversely proportional to the total muscular mass. Moreover, if the augmented REE/FFM were due to an increased metabolism of the visceral organs, we should have found some alterations in bio-humoral parameters (Gelfand et al., 1987; Izamis et al., 2012). On the contrary COL6-RM subjects do not show any important variation in blood or urine biochemical assays.

Additionally, there was no correlation between the REE/FM and the clinical status portrayed by Megascore analysis (Figure 4). Therefore, we can exclude increased adipocytes energy expenditure as a source of the hypermetabolic state.

Finally, recent discoveries about mitochondrial metabolism (Bernardi and Bonaldo, 2008; Shaham et al., 2010) offer a possible biochemical explanation of the increased REE/FFM ratio. In particular, Bernardi et al. have found important alterations in mitochondrial membrane permeability due to the ColA6 mutation. The lack of Collagen VI causes increased transient openings of the Permeability Transition Pore ion channel in the mitochondrial inner membrane, with consequent mitochondrial depolarization and energy dissipation. This leads to a switch of the ATP synthase into an ATP hydrolase with a progressive impairment of respiration which may be responsible for the augmented REE spent by the muscular mass. This pathophysiology mechanism may explain our findings.

We also discovered that the metabolic substrates consumed by these patients are strictly related to their FFM (Figures $\mathbf{2}$ and $\mathbf{3}$ ). In particular, patients with higher FFM have a carbohydrate-based metabolism, while the ones with lower FFM prevalently use fatty acids as metabolic substrates. These findings suggest that patients with a relatively greater FFM have more muscular mass, and consequently an increased glycogen reserve to be used, compared to patients with lower FFM (Tsujino et al., 2000). On the other hand, the fat-based metabolism is explained by the increasing fat infiltration with disease progression; the depletion of muscular mass and the correlated decrement in glycogen storage lead to a metabolic shift toward burning fatty acids, whose reserves increase and infiltrate muscular tissue (Tagliavini et al., 2014). These evidences suggest that the worsening of the pathology is closely correlated to important changes in muscle metabolism.

Another significant result is the correlation between FFM and muscle strength, summarized by the Megascore (Figure 5). Other studies have previously demonstrated that Megascore is a good indicator of patients' muscular efficiency, paralleling muscle function (Merlini et al., 2002, 2004). Hence, the correlation between muscle Megascore and FFM is more a portrait of the muscular mass and its efficiency, rather than of visceral organ activity.
The strong correlations between Megascore and appendicular LM, where the non-muscle component of FFM is minimal, support this hypothesis.

This is a perfect expression of the concept of functional body composition: in COL6-RM, a pure body composition parameter like appendicular LM is directly correlated to muscular strength (Megascore) and contributes to the diagnosis of sarcopenia, a condition in which the loss of skeletal muscle mass is associated with lower muscle strength and function (Abellan Baumgartner et al., 1998; van Kan et al., 2012)

Creatinine is derived from the metabolism of creatine, which is transformed into phosphocreatine and used by muscles as an energetic substrate (Hoagland et al., 1945). A higher production of creatinine is linked to a higher use of phosphocreatine and, consequently, to greater muscular efficiency. In order to confirm this hypothesis, and to exclude any artifact due to individual body composition, we have analyzed the $\mathrm{CHI}$, which evaluates urinary creatinine levels by normalizing the individual differences among subjects (Rosenfalck et al., 1994). Even in this case, the $\mathrm{CHI}$ scores perfectly correlate to the muscle strength, as evaluated by Megascore (Figure 6).

Hence, even if Franciotta et al. (2003) declare that urinary creatinine is not a good predictive indicator of skeletal muscular mass in Duchenne dystrophy; our results suggest that it is a good indicator of muscular performance.

Another important correlation is the one between blood creatinine and Megascore. Even if we have to consider renal filtration, blood creatinine gives an instant picture of the muscle metabolism (Baxmann et al., 2008). The probability of finding circulating creatinine is directly proportional to the quantity of phosphocreatine produced and used by muscle cells. Considering our results about urinary creatinine and $\mathrm{CHI}$, this finding confirms the previous ones.

All in all, in this study, we have pointed out the importance of a nutritional approach to genetically based pathologies, such as UCMD and BM diseases. Additionally, we have underlined the necessity of a functional body composition analysis, which could be a powerful clinical tool for patients' follow-up and prognosis.

The main limit of our study is represented by the scant number of recruited patients, caused by the rarity of these pathologies; hence, our conclusions should be confirmed by the analysis of a wider sample of subjects.

Our results confirm and complete what has been reported in the literature about collagen VI myopathies, further supporting the rationale for nutritional interventions aimed at correcting the metabolic imbalance and maintaining the patient's muscular mass.

\section{AUTHOR CONTRIBUTIONS}

Silvia Toni made substantial contributions to acquisition of the data, carried out the nutritional evaluation, and performed the statistical analysis. Riccardo Morandi and Marcello Busacchi substantially contributed by discussing the data, writing the manuscript, and performing statistical analysis. Lucia Tardini contributed to the acquisition of data and carried out the anthropometric evaluation. Luciano Merlini conceived the study and participated in its design and coordination. Nino Carlo Battistini evaluated the 
body composition data. Massimo Pellegrini participated in the design of the study, contributed to the statistical analysis, and has contributed substantially in the interpretation of data.

\section{ACKNOWLEDGMENTS}

This study was supported by Grant no. GUP11007 (Luciano Merlini) from Telethon, Italy.

\section{REFERENCES}

Allamand, V., Merlini, L., Bushby, K., and Consortium for Collagen VI-Related Myopathies. (2010). 166th ENMC international workshop on collagen type VIrelated myopathies, 22-24 May 2009, naarden, The Netherlands. Neuromuscul. Disord. 20, 346-354. doi:10.1016/j.nmd.2010.02.012

Ballesteros, M., Cortes, A., Arleaga, C. I., Puerto, R., and Bojac, B. (1994). [The usefulness of serum creatinine levels in identifying hospital malnutrition]. Nutr. Hosp. 9, 186-196.

Baumgartner, R. N., Koehler, K. M., Gallagher, D., Romero, L., Heymsfield, S. B., Ross, R. R., et al. (1998). Epidemiology of sarcopenia among the elderly in New Mexico. Am. J. Epidemiol. 147, 755-763. doi:10.1093/oxfordjournals.aje. a009520

Baumgartner, R. N., Wayne, S. J., Waters, D. L., Janssen, I., Gallagher, D., and Morley, J. E. (2004). Sarcopenic obesity predicts instrumental activities of daily living disability in the elderly. Obes. Res. 12, 1995-2004.

Baxmann, A. C., Ahmed, M. S., Marques, N. C., Menon, V. B., Pereira, A. B., Kirsztajn, G. M., et al. (2008). Influence of muscle mass and physical activity on serum and urinary creatinine and serum cystatin C. Clin. J. Am. Soc. Nephrol. 3, 348-354. doi:10.2215/CJN.02870707

Beenakker, E. A., van der Hoeven, J. H., Fock, J. M., and Maurits, N. M. (2001). Reference values of maximum isometric muscle force obtained in 270 children aged 4-16 years by hand-held dynamometry. Neuromuscul. Disord. 11, 441-446. doi:10.1016/S0960-8966(01)00193-6

Bernardi, P., and Bonaldo, P. (2008). Dysfunction of mitochondria and sarcoplasmic reticulum in the pathogenesis of collagen VI muscular dystrophies. Ann. N. Y. Acad. Sci. 1147, 303-311. doi:10.1196/annals.1427.009

Bernardi, P., and Bonaldo, P. (2013). Mitochondrial dysfunction and defective autophagy in the pathogenesis of collagen VI muscular dystrophies. Cold Spring Harb. Perspect. Biol. 5, a011387. doi:10.1101/cshperspect.a011387

Bertini, E., and Pepe, G. (2002). Collagen type VI and related disorders: Bethlem myopathy and Ullrich scleroatonic muscular dystrophy. Eur. J. Paediatr. Neurol. 6, 193-198. doi:10.1053/ejpn.2002.0593

Bryan, W. W., Hoagland, R. J., Murphy, J., Armon, C., Barohn, R. J., Goodpasture, J. C., et al. (2003). Can we eliminate placebo in ALS clinical trials? Amyotroph. Lateral Scler. Other Motor Neuron Disord. 4, 11-15. doi:10.1080/14660820310006661

De Palma, S., Leone, R., Grumati, P., Vasso, M., Polishchuk, R., Capitanio, D., et al. (2013). Changes in muscle cell metabolism and mechanotransduction are associated with myopathic phenotype in a mouse model of collagen VI deficiency. PLOS ONE 8:e56716. doi:10.1371/journal.pone.0056716

El Ghoch, M., Milanese, C., Calugi, S., Pellegrini, M., Battistini, N. C., and Dalle Grave, R. (2014). Body composition, eating disorder psychopathology, and psychological distress in anorexia nervosa: a longitudinal study. Am. J. Clin. Nutr. 99, 771-778. doi:10.3945/ajcn.113.078816

Elliott, S. A., Davidson, Z. E., Davies, P. S. W., and Truby, H. (2012). Predicting resting energy expenditure in boys with Duchenne muscular dystrophy. Eur. J. Paediatr. Neurol. 16, 631-635. doi:10.1016/j.ejpn.2012.02.011

Franciotta, D., Zanardi, M. C., Albertotti, L., Orcesi, S., Berardinelli, A., Pichiecchio, A., et al. (2003). Measurement of skeletal muscle mass in Duchenne muscular dystrophy: use of 24-h creatinine excretion. Acta Diabetol. 40(Suppl. 1), S290-S292. doi:10.1007/s00592-003-0089-8

Gelfand, R. A., Hutchinson-Williams, K. A., Bonde, A. A., Castellino, P., and Sherwin, R. S. (1987). Catabolic effects of thyroid hormone excess: the contribution of adrenergic activity to hypermetabolism and protein breakdown. Metab. Clin. Exp. 36, 562-569. doi:10.1016/0026-0495(87)90168-5

Gonzalez-Bermejo, J., Lofaso, F., Falaize, L., Lejaille, M., Raphaël, J.-C., Similowski, T., et al. (2005). Resting energy expenditure in Duchenne patients using home mechanical ventilation. Eur. Respir. J. 25, 682-687. doi:10.1183/09031936.05. 00031304
Grumati, P., Coletto, L., Sabatelli, P., Cescon, M., Angelin, A., Bertaggia, E., et al. (2010). Autophagy is defective in collagen VI muscular dystrophies, and its reactivation rescues myofiber degeneration. Nat. Med. 16, 1313-1320. doi:10. 1038/nm.2247

Gualandi, F., Urciuolo, A., Martoni, E., Sabatelli, P., Squarzoni, S., Bovolenta, M., et al. (2009). Autosomal recessive Bethlem myopathy. Neurology 73, 1883-1891. doi:10.1212/WNL.0b013e3181c3fd2a

Heymsfield, S. B., Gallagher, D., Kotler, D. P., Wang, Z., Allison, D. B., and Heshka, S. (2002). Body-size dependence of resting energy expenditure can be attributed to nonenergetic homogeneity of fat-free mass. Am. J. Physiol. Endocrinol. Metab. 282, E132-E138.

Hoagland, C. L., Gilder, H., and Shank, R. E. (1945). The synthesis, storage, and excretion of creatine, creatinine, and glycocyamine in progressive muscular dystrophy and the effects of certain hormones on these processes. J. Exp. Med. 81, 423-438. doi:10.1084/jem.81.5.423

Hogan, S. E. (2008). Body composition and resting energy expenditure of individuals with Duchenne and Becker muscular dystrophy. Can. J. Diet. Pract. Res. 69, 208-212. doi:10.3148/69.4.2008.208

Irwin, W. A., Bergamin, N., Sabatelli, P., Reggiani, C., Megighian, A., Merlini, L., et al. (2003). Mitochondrial dysfunction and apoptosis in myopathic mice with collagen VI deficiency. Nat. Genet. 35, 367-371. doi:10.1038/ng1270

Izamis, M.-L., Uygun, K., Sharma, N. S., Uygun, B., Yarmush, M. L., and Berthiaume, F. (2012). Development of metabolic indicators of burn injury: very low density lipoprotein (vldl) and acetoacetate are highly correlated to severity of burn injury in rats. Metabolites 2, 458-478. doi:10.3390/metabo2030458

Janssen, I., Katzmarzyk, P. T., and Ross, R. (2002). Body mass index, waist circumference, and health risk: evidence in support of current National Institutes of Health guidelines. Arch. Intern. Med. 162, 2074-2079. doi:10.1001/archinte.162. 18.2074

Jarraya, M., Quijano-Roy, S., Monnier, N., Béhin, A., Avila-Smirnov, D., Romero, N. B., et al. (2012). Whole-body muscle MRI in a series of patients with congenital myopathy related to TPM2 gene mutations. Neuromuscul. Disord. 22(Suppl. 2), S137-S147. doi:10.1016/j.nmd.2012.06.347

Jukema, J. W., and Simoons, M. L. (1999). Treatment and prevention of coronary heart disease by lowering serum cholesterol levels; from the pioneer work of C.D. de Langen to the third "Dutch consensus on cholesterol.". Acta Cardiol. 54, 163-168.

Kanis, J. A., McCloskey, E. V., Johansson, H., Cooper, C., Rizzoli, R., and Reginster, J.Y. (2013). European guidance for the diagnosis and management of osteoporosis in postmenopausal women. Osteoporos. Int. 24, 23-57. doi:10.1007/s00198-0122074-y

Kelly, T. L., Wilson, K. E., and Heymsfield, S. B. (2009). Dual energy X-ray absorptiometry body composition reference values from NHANES. PLoS ONE 4:e7038. doi:10.1371/journal.pone.0007038

Livesey, G., and Elia, M. (1988). Estimation of energy expenditure, net carbohydrate utilization, and net fat oxidation and synthesis by indirect calorimetry: evaluation of errors with special reference to the detailed composition of fuels. Am. J. Clin. Nutr. 47, 608-628.

Lohman, T. G., Martorell, R., and Roche, A. F. (1988). Anthropometric Standardization Reference Manual. Champaign IL: Human Kinetics Books.

McArdle, W. D., Katch, F. I., and Katch, V. L. (1986). Exercise Physiology Energy, Nutrition, and Human Performance. Philadelphia: Lea \& Febiger.

Mercuri, E., Lampe, A., Allsop, J., Knight, R., Pane, M., Kinali, M., et al. (2005). Muscle MRI in Ullrich congenital muscular dystrophy and Bethlem myopathy. Neuromuscul. Disord. 15, 303-310. doi:10.1016/j.nmd.2005.01.004

Merlini, L., Angelin, A., Tiepolo, T., Braghetta, P., Sabatelli, P., Zamparelli, A., et al. (2008a). Cyclosporin A corrects mitochondrial dysfunction and muscle apoptosis in patients with collagen VI myopathies. Proc. Natl. Acad. Sci. U. S. A. 105, 5225-5229. doi:10.1073/pnas.0800962105

Merlini, L., Martoni, E., Grumati, P., Sabatelli, P., Squarzoni, S., Urciuolo, A., et al. (2008b). Autosomal recessive myosclerosis myopathy is a collagen VI disorder. Neurology 71, 1245-1253. doi:10.1212/01.wnl.0000327611.01687.5e

Merlini, L., Bertini, E., Minetti, C., Mongini, T., Morandi, L., Angelini, C., et al. (2004). Motor function-muscle strength relationship in spinal muscular atrophy. Muscle Nerve 29, 548-552. doi:10.1002/mus.20018

Merlini, L., Mazzone, E. S., Solari, A., and Morandi, L. (2002). Reliability of hand-held dynamometry in spinal muscular atrophy. Muscle Nerve 26, 64-70. doi:10.1002/mus. 10166 
Merlini, L., Morandi, L., Granata, C., and Ballestrazzi, A. (1994). Bethlem myopathy: early-onset benign autosomal dominant myopathy with contractures. Description of two new families. Neuromuscul. Disord. 4, 503-511. doi:10.1016/ 0960-8966(94)90091-4

Merlini, L., Nishino, I., and Consortium for Autophagy in Muscular Dystrophies. (2014). 201st ENMC international workshop: autophagy in muscular dystrophies - translational approach, 1-3 november 2013, Bussum, The Netherlands. Neuromuscul. Disord. 24, 546-561. doi:10.1016/j.nmd.2014.03.009

Merlini, L., Solari, A., Vita, G., Bertini, E., Minetti, C., Mongini, T., et al. (2003). Role of gabapentin in spinal muscular atrophy: results of a multicenter, randomized Italian study. J. Child Neurol. 18, 537-541. doi:10.1177/ 08830738030180080501

Mifflin, M. D., St Jeor, S. T., Hill, L. A., Scott, B. J., Daugherty, S. A., and Koh, Y. O. (1990). A new predictive equation for resting energy expenditure in healthy individuals. Am. J. Clin. Nutr. 51, 241-247.

Miscione, M. T., Bruno, F., Ripamonti, C., Nervuti, G., Orsini, R., Faldini, C., et al. (2013). Body composition, muscle strength, and physical function of patients with Bethlem myopathy and Ullrich congenital muscular dystrophy. Scientific World Journal 2013:152684. doi:10.1155/2013/152684

Moon, J. R., Tobkin, S. E., Smith, A. E., Roberts, M. D., Ryan, E. D., Dalbo, V. J., et al. (2008). Percent body fat estimations in college men using field and laboratory methods: a three-compartment model approach. Dyn. Med. 7, 7. doi:10.1186/1476-5918-7-7

Müller, M. J. (2007). Malnutrition and hypermetabolism in patients with liver cirrhosis. Am. J. Clin. Nutr. 85, 1167-1168.

Müller, M. J., Bosy-Westphal, A., Later, W., Haas, V., and Heller, M. (2009). Functional body composition: insights into the regulation of energy metabolism and some clinical applications. Eur. J. Clin. Nutr. 63, 1045-1056. doi:10.1038/ejcn.2009.55

Norwood, F. L. M., Harling, C., Chinnery, P. F., Eagle, M., Bushby, K., and Straub, V. (2009). Prevalence of genetic muscle disease in Northern England: in-depth analysis of a muscle clinic population. Brain 132, 3175-3186. doi:10.1093/brain/awp236

O’Connor, L. M., Lentjes, M. A. H., Luben, R. N., Khaw, K.-T., Wareham, N. J., and Forouhi, N. G. (2014). Dietary dairy product intake and incident type 2 diabetes: a prospective study using dietary data from a 7-day food diary. Diabetologia 57, 909-917. doi:10.1007/s00125-014-3176-1

Pepe, G., de Visser, M., Bertini, E., Bushby, K., Vanegas, O. C., Chu, M. L., et al. (2002). Bethlem myopathy (BETHLEM) 86th ENMC international workshop, 10-11 November 2000, Naarden, The Netherlands. Neuromuscul. Disord. 12, 296-305. doi:10.1016/S0960-8966(01)00275-9

Rohan, T. E., Heo, M., Choi, L., Datta, M., Freudenheim, J. L., Kamensky, V., et al. (2013). Body fat and breast cancer risk in postmenopausal women: a longitudinal study. J. Cancer Epidemiol. 2013, 754815. doi:10.1155/2013/754815

Rosenfalck, A. M., Snorgaard, O., Almdal, T., and Binder, C. (1994). Creatinine height index and lean body mass in adult patients with insulin-dependent diabetes mellitus followed for 7 years from onset. JPEN J. Parenter. Enteral Nutr. 18, 50-54. doi:10.1177/014860719401800150

Roza, A. M., and Shizgal, H. M. (1984). The Harris Benedict equation reevaluated: resting energy requirements and the body cell mass. Am. J. Clin. Nutr. 40, $168-182$.

Scaglioni, F., Marino, M., Ciccia, S., Procaccini, A., Busacchi, M., Loria, P., et al. (2013). Short-term multidisciplinary non-pharmacological intervention is effective in reducing liver fat content assessed non-invasively in patients with nonalcoholic fatty liver disease (NAFLD). Clin. Res. Hepatol. Gastroenterol. 37, 353-358. doi:10.1016/j.clinre.2012.10.009

Shaham, O., Slate, N. G., Goldberger, O., Xu, Q., Ramanathan, A., Souza, A. L., et al. (2010). A plasma signature of human mitochondrial disease revealed through metabolic profiling of spent media from cultured muscle cells. Proc. Natl. Acad. Sci. U. S. A. 107, 1571-1575. doi:10.1073/pnas.0906039107
Tagliavini, F., Sardone, F., Squarzoni, S., Maraldi, N. M., Merlini, L., Faldini, C., et al. (2014). Ultrastructural changes in muscle cells of patients with collagen VI-related myopathies. Muscles Ligaments Tendons J. 3, 281-286.

Tarnopolsky, M. A., MacDougall, J. D., and Atkinson, S. A. (1988). Influence of protein intake and training status on nitrogen balance and lean body mass. J. Appl. Physiol. 1985, 187-193.

Tsujino, S., Nonaka, I., and DiMauro, S. (2000). Glycogen storage myopathies. Neurol. Clin. 18, 125-150. doi:10.1016/S0733-8619(05)70181-X

Tuffery-Giraud, S., Saquet, C., Chambert, S., Echenne, B., Marie Cuisset, J., Rivier, F., et al. (2004). The role of muscle biopsy in analysis of the dystrophin gene in Duchenne muscular dystrophy: experience of a national referral centre. Neuromuscul. Disord. 14, 650-658. doi:10.1016/j.nmd.2004.05.002

Turell, D. J., and Alexander, J. K. (1964). Experimental evaluation of weir's formula for estimating metabolic rate in man. J. Appl. Physiol. 19, 946-948.

Vaisman, N., Katzenellenbogen, S., and Nevo, Y. (2004). Increased resting energy expenditure in subjects with Emery-Dreifuss muscular dystrophy. Neuromuscul. Disord. 14, 142-146. doi:10.1016/j.nmd.2003.10.012

Van der Ploeg, R. J., Fidler, V., and Oosterhuis, H. J. (1991). Hand-held myometry: reference values. J. Neurol. Neurosurg. Psychiatry 54, 244-247. doi:10.1136/jnnp. 54.3.244

van Kan, G., Houles, M., and Vellas, B. (2012). Identifying sarcopenia. Curr. Opin. Clin. Nutr. Metab. Care 15, 436-441. doi:10.1097/MCO.0b013e328356bbf4

Wang, Z., Heymsfield, S. B., Chen, Z., Zhu, S., and Pierson, R. N. (2010). Estimation of percentage body fat by dual-energy $\mathrm{x}$-ray absorptiometry: evaluation by in vivo human elemental composition. Phys. Med. Biol. 55, 2619-2635. doi:10.1088/0031-9155/55/9/013

Willis, T. A., Hollingsworth, K. G., Coombs, A., Sveen, M.-L., Andersen, S., Stojkovic, T., et al. (2014). Quantitative magnetic resonance imaging in limb-girdle muscular dystrophy 2I: a multinational cross-sectional study. PLoS ONE 9:e90377. doi:10.1371/journal.pone.0090377

Wohlfahrt, P., Somers, V. K., Sochor, O., Kullo, I., Jean, N., and Lopez-Jimenez, F. (2014). Influence of body fatness distribution and total lean mass on aortic stiffness in nonobese individuals. Am. J. Hypertens doi:10.1093/ajh/hpu153

Energy and protein requirements. Report of a joint FAO/WHO/UNU expert consultation. (1985). World Health Organ. Tech. Rep. Ser 724, 1-206.

Zanardi, M. C., Tagliabue, A., Orcesi, S., Berardinelli, A., Uggetti, C., and Pichiecchio, A. (2003a). Body composition and energy expenditure in Duchenne muscular dystrophy. Eur. J. Clin. Nutr. 57, 273-278. doi:10.1038/sj.ejcn.1601524

Zanardi, M. C., Tagliabue, A., Orcesi, S., Berardinelli, A., Uggetti, C., and Pichiecchio, A. (2003b). Body composition and energy expenditure in Duchenne muscular dystrophy. Eur. J. Clin. Nutr. 57, 273-278. doi:10.1038/sj.ejcn.1601524

Conflict of Interest Statement: The authors declare that the research was conducted in the absence of any commercial or financial relationships that could be construed as a potential conflict of interest.

Received: 30 June 2014; accepted: 26 October 2014; published online: 17 November 2014.

Citation: Toni S, Morandi R, Busacchi M, Tardini L, Merlini L, Battistini NC and Pellegrini $M$ (2014) Nutritional status evaluation in patients affected by Bethlem myopathy and Ullrich congenital muscular dystrophy. Front. Aging Neurosci. 6:315. doi: 10.3389/fnagi.2014.00315

This article was submitted to the journal Frontiers in Aging Neuroscience.

Copyright (c) 2014 Toni, Morandi, Busacchi, Tardini, Merlini, Battistini and Pellegrini. This is an open-access article distributed under the terms of the Creative Commons Attribution License (CC BY). The use, distribution or reproduction in other forums is permitted, provided the original author(s) or licensor are credited and that the original publication in this journal is cited, in accordance with accepted academic practice. No use, distribution or reproduction is permitted which does not comply with these terms. 